\title{
PHYSICAL THERAPY IN LEPROSY
}

\section{S. AlDERSON}

It is considered by the British Empire Leprosy Relief Association that physical medicine in the form of physiot and occupational therapy has an important part to play in the treatment of leprosy.

In assessing the value of physical treatment the economic aspect of these disabilities must be taken into account. Large numbers of patients throughout the world are manual workers. Advanced stages of main-en-griffe, especially if accompanied by fore-shortening of the fingers make the use of implements and tools extremely difficult, and in many cases quite impossible. This can 
obviously lead to hardship both when the patient is in the settlement and after he has been discharged. Although arrangements can be made in some settlements for help to be given to crippled patients it is doubtful if it is, or can be, offered to all. Outside the settlement it is very often the case that the cripple is looked upon as a useless member of the community and left to his own quite inadequate resources. Some patients even prefer to stay in the settlement after discharge, having this fact in mind.

The psychological outlook is also of major importance. It is disturbing to the patient to feel that, although he is experiencing general improvement yet the disability of his hand or foot or both is increasing. This leads to the apparent anomaly of a patient entering a settlement with a whole body and leaving it symptom free with physical deformities of the limbs. Confidence in the general treatment is not encouraged under these circumstances.

Our aim is, therefore, to remedy as far as possible the existing cases of muscular atrophy and contractures and, in the case of patients complaining of painful and enlarged nerves, to prevent the consequent trophic changes.

In order to confirm the necessity for physical treatment, a survey of contractures was carried out among patients at a number of Nigerian settlements. This survey was of a reconnaissance type, and covered all kinds of contractures. Dupuytren's contracture is common in Nigeria, probably being exacerbated by the extensive use of machetes, and on the coast in the Creeks Area, by the use of canoe paddles. Yaws is, of course, widespread and leaves behind many deformed hands. Taking all non leprotic contractures into account, however, the number of leprotic contractures is very high.

A further survey was carried out at the Uzuakoli settlement. This included all stages of main-en-griffe. The survey was made in considerable detail and dealt specifically with the ulnar nerve. Examination was made for pain, nerve enlargement, muscular atrophy, contracture and foreshortening of the fingers. This survey brought a number of interesting points to light. The number of potential cases is as great, in fact slightly greater, than the number of cases where trophic changes are evident. This is especially so in the case of the children where 74 out of IOI affected cases showed trophic changes. Of the 378 affected cases II \% had their left arm only affected, $25 \%$ their right arm only, and $65 \%$ both arms affected.

Dr. Ross undertook a survey of 194 patients. Of these 50 $(26 \%)$ showed signs of nerve involvement with slight wasting and involvement of muscles and eminences; 24 (12\%) showed marked 
signs of wasting with contracture; $13(7 \%)$ showed an advanced stage of wasting of all muscles of the hand and contracture. This gives a total of $45 \%$ affected of cases examined. It is again evident that the early cases are in the majority.

It proved difficult to find an occupation having a remedial value for main-en-griffe; one which, having in mind the patient's lack of co-operation, definitely necessitated the use of the little, ring, and middle fingers. The only type of equipment which seemed to offer itself was a hand-operated table loom based on a Dryad design modified by Miss McCaul, M.A.O.T. of the London Hospital. This had been used to encourage flexion of fingers and wrist, and to increase hand-grip. A number of these looms were made. Their operation was carried out by the turning of cylindrical wooden handles about 6 " long. These were detachable and of varying diameters. For leprotic contractures the handles were reversed in order of use, progressively larger handles being used. A range of eight sizes was kept, from I" to $2 \frac{3}{4}{ }^{\prime \prime}$ diameter in

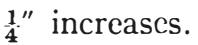

Each patient's hand was " fitted" individually, the largest handle that a patient could comfortably use being given first. Each patient was re-examined at intervals, and the next largest size given if warranted. These looms were used over a period of seven months, and produced very satisfactory results. They had drawbacks, however. Although they experienced a certain initial popularity, this soon waned. The popularity was due to the fact that knowledge of weaving on a European loom was considereil to be of potential economic value. Also, there seemed a possibility that the material woven, 2 " bandages, might become the patient's own upon its completion. When the novelty wore off, and the latter possibility failed to materialise the popularity waned.

The five principal exercises adopted were:-

(I) Fingers of one hand interlocking with those of the other, palms facing away from the body, arms bent at the elbows. Exercise by straightening arms. The fingers are thus forcibly extended against the back of the opposite hand.

(2) Forearms horizontal against the body, palms of hands touching, both hands vertical. Exercise by abducting all the fingers fully and then pressing opposite numbers and abducting the fingers so that all fingers and thumb tips close in to touch each other, at the same time allowing arms to be separated.

(3) Hand placed palm upwards on the table. Exercise by 
stretching and flexing fingers by touching the ball of the thumb with each finger tip in turn.

(4) Same position. Exercise by touching each finger tip with the thumb, seeing that the fingers do not move.

(5) Making a cup out of the palm of the hand with the finger tips close together and the knuckles slightly bent. Exercise by bringing the little finger in front of the others.

Two excrcises with simple apparatus were found most satisfactory. One was carried out with a flat stick about $3^{\prime} 6^{\prime \prime}$ long. issued to each patient. On one side, marks were made showing the position of each finger when they were all fully abducted, care being taken that the hand was held flat. On the other side similar marks were made with the hand held vertically down over the stick and the fingers "walking" along it. The marks were made on the first day of treatment making sure that there was no strain. This also served as a guide to improvement.

The other was designed to give resistance to flexion of the fingers. It consisted of a flat rectangular piece of wood with a semi-circular inset to receive the ends of the fingers and so prevent slipping. Two strings were attached to the wood and from these hung a container partially filled with sand. The forearm was placed in the supine position upon the table, the finger tips overhanging. The rectangle was placed upon the ends of the fingers and the fingers flexed against the weight of the suspended sand. The latter could be varied in quantity to vary the degree of resistance as required.

Heat treatment took the form of baths of paraffin wax and, alternatively, hydnocarpus oil. The only paraffin wax available had a very high melting point and even when mixed with liquid paraffin a temperature of $120^{\circ} \mathrm{C}$ was required. This created no difficulty but wasted time. It took a considerable time to cool down to $100^{\circ}-105^{\circ} \mathrm{C}$ because of the high atmospheric temperature. In application it proved quite satisfactory. The draw-back was that children always broke the wax "glove" at the wrist if triple immersion was adopted, because large deep containers were not available and basins had to be used with larger basins to hold the water jacket. Ladling was tried but there never seemed to be enough wax on the inside of the "glove." These faults could be overcome with adequate equipment.

The oil bath on the other hand was very much simpler and for this reason alone might be considered preferable. Using a pressure stove (primus type) it took only a few minutes to bring the temperature up to $100^{\circ} \mathrm{C}$, at which it could be used directly. 
The saving of time was considerable and the hydnocarpus oil acted as an excellent lubricant for the massage which followed. The oil bath was used for the most part and wax only for those patients who were prepared to take more time on their treatment, and for patients whose fingers, although not necessarily contracted, were stiff and lacking in normal function.

Massage was given for periods of from five to fifteen minutes immediately following heat treatment. This consisted of effleurage, kneading and friction. The effleurage, was given to the whole of the hand and, later, to the forearm along the ulnar border. Finger kneading was given to all the muscles of the ulnar distribution in the hand, especially the interossei and the hypothenar eminence. Friction was given to all the fingers.

The introduction of these forms of treatment took a few months. By this time it became evident that the treatment given should be standardised. This made the work easier for the staff to carry out, especially when working with a "class" of children and adults at the same time. Thus a standard treatment was introduced which consisted of heat treatment followed by active finger exercises. In the case of a class consisting of, say, six or more children the loom proved useful as a "filler" between the massage and exercises. As at this time there were two patientassistants it was possible to massage only two patients at one time. Therefore, the drill was for two to be oil-bathing their hands, two being massaged, whilst the rest operated looms either waiting to receive this treatment, or, having received it, waiting for the others to finish. When all had been given the heat treatment and massage one assistant called them together and took them in the active exercises, finishing with the " stick" exercises, If any time remained they were put back on to the looms. Adults were treated individually.

Each new case was given a thorough examination by the European in charge, the results being recorded on a printed case sheet. Tests were made for anæsthesia to light touch, pain and thermal sensation muscles of the hand were tested for weakness; note was made of trophic changes and pain. Personal details were noted. Type of remedial treatment was specified and entered with dates; daily attendance was recorded on the reverse side. The assistant was then given the treatment instructions which he noted in his treatment book, one page was kept for each patient and daily attendances were recorded.

Occupational therapy in the form of the hand loom described was efficacious. The principal drawback was its lack of popularity with adult patients, especially the men. Children could be made 
to use the looms, women could be induced to clo so, but the men, for the main part, objected. This type of treatment in particular requires full co-operation with the patient in order to be of any great benefit. Its full range of movement was not sufficient by itself and it cost time to set up the looms after each woven bandage was completed. The looms were quite simple and inexpensive to construct, the bandages made proved superior to manufactured ones when applied to ulcerated feet.

The following case sheets demonstrated results achieved.

CASE A.

A boy of I6 years. Admitted to settlement in I 945 . Date of onset of disease was 1937. Date of onset of disability was 1945. Disability: Severe main-en-griffe of left hand, nerves affected; the ulnar was slightly enlarged; muscle weakness; all flexors very weak; almost complete loss of function of interossei. Contracture: Moderate over fifth, fourth, and third fingers. Atrophy and severe wasting of all interossei and the two eminences; metacarpals prominent on both aspects. Pain: None. Physical condition: Good generally, prognosis was good. Attendance: Good, but treatment was missed for a period of nearly three months due to school holidays and an extended visit home.

The treatment commenced in October, 1947. Very favour. able reaction was shown in abduction and especially in flexion. The fingers became more flexible and considerable strength was developed in the flexors, the contracture was obviously reduced.

Later on more attention was paid to the interessei, and more abduction exercises were carried out.

At this time, May, 1948, a record was made of the hand with the fingers fully abducted. Six weeks later a check was made for increased abduction. This was found to be $\frac{1}{2}$ " over the four fingers and $I^{\prime \prime}$ between the thumb and index finger. Over the same period the degree of contracture was recorded also. The distance was measured from a flat surface to the underneath side of each finger at the proximal inter-phalangeal joint. In this length of time the distance had been reduced by I/IO" for each finger. The patient was pleased with the progress and became increasingly co-operative.

CASE B.

A woman aged 45 years. Date of onset of disability 1946 (?). Type of disability: Main-en-griffe of both hands, the left hand 
was more severe than the right. \&( )nly the left hand will be described here.] Nerve affected: the ulnar was greatly enlarged for 4" above the elbow. Muscle weakness: considerable in flexors, power of extension very weak. Power of abduction and adduction of second finger was slight, with that of fourth almost absent, and that of fifth completely absent. Contracture: Consiclerable in the fifth, fourth, third, and second fingers. Atrophy: Both eminences and the interossei showed wasting. Pain experienced in ulnar nerve, particularly in the upper arm. Physical condition: Mioderately good. Treatment commenced: Io/I I/47 and was continuous.

It proved very satisfactory, the pain was alleviated progressively, the range of movement increased and general mobility of the hand and arm improved. Records of progress were kept over six weeks and showed an increase in adduction.

Exercises, based on a monograph by Dr. Ryric, were introduced into the school curriculum at one of the settlements. Exercises chosen for their remedial and preventive value for both arms and legs were carried out in the P.T. and games period, and finger exercises were carried out in the class rooms between periods. These proved successful and should be carried out in all settlements.

Regarding staff it was found that satisfactory assistants could be found amongst the patients. It proved fairly simple to teacir them the elements of the work and they learned quickly.

The figures of the three surveys proved beyond doubt the necessity for the introduction of physical treatment both in its remedial and preventive forms. This applies especially to children where the number of cases showing involvement of the ulnar nerve only, is two to three times greater than those cases showing trophic changes.

In spite of the comparatively short duration of the experimental work and its improvised nature, the results obtained prove the possibility of introducing physical therapy successfully into leprosy settlements.

A physical treatment centre provides no great obstacle. African assistants can be found from among the patients and, although the inception of a centre requires a good deal of time and work on the part of a European, the routine work of an established centre can be included with that of a Welfare Officer. The 
cost of establishing a centre is small, the main item being the provision of Primus stoves and large basins or containers for wax and oil. Even if occupational therapy is introduced the cost of making the looms described is comparatively small. Running expenses consist of little more than the salaries of African assistants. If these are colony patients then the amount is very small.

Classification of cases was discussed with Dr. Ross at considerable length, having in mind the parts which physical treatment and operative surgery might play in ulnar nerve involvement and consequent disabilities. Those which suggested themselves were:

Early Stage

(a) Cases with enlarged and acutely painful nerve, but with no physical signs. If the patient has acute neuritis with loss of function of the hand, the case requires primarily injection therapy or operative surgery.

(b) Cases with enlarged but not acutely painful nerves. Physical treatment should be tried for this type of case. If disability or loss of function becomes evident in spite of physical treatment then operative methods should be considered.

(c) Cases with neuritis and slight signs of muscular atrophy. If neuritis is slight and the nerve is generally enlarged longitudinally, physical treatment should be tried, but if the nerve is enlarged, bulbous, tense and tender, operative methods should be considered.

\section{Advanced Stages}

Pain is less a feature in these cases than in those of the early stages and physical signs are more marked. The nerve is fibrous but not necessarily tender; atrophy and contracture are present. Physical treatment should be given in these cases.

\section{Post-Operative Cases}

These should all be given physical treatment.

It is hoped that this report will prove the desirability and the necessity for physical medicine and offer a basis upon which treatment might be generally established. 


\section{SURVEYS}

SURVEY OF CONTRACTURES.

Oji River Settlement.

\begin{tabular}{|c|c|c|c|c|c|c|}
\hline \multicolumn{3}{|l|}{ Type of Case } & Men & II"omen & Children & Total \\
\hline Early Cases & $\ldots$ & $\ldots$ & 44 & I9 & 36 & 99 \\
\hline Advanced Cases .. & $\ldots$ & $\ldots$ & 54 & I 8 & .35 & I07 \\
\hline Total Affected .. & $\ldots$ & $\ldots$ & 98 & 37 & $7 \mathrm{I}$ & 206 \\
\hline Cotal Examined .. & $\ldots$ & $\ldots$ & 218 & I3I & 285 & 634 \\
\hline Affec & $\ldots$ & & 45 & 28 & 25 & 32 \\
\hline
\end{tabular}

Ossimo Settlement.

\begin{tabular}{lcccccc}
\multicolumn{2}{c}{ Type of Case } & & Men & Women & Cbildien & Total \\
Early Cases & $\ldots$ & $\ldots$ & 67 & I7 & 32 & II6 \\
Advanced Cases & $\ldots$ & $\ldots$ & 136 & I5 & 30 & 18I \\
Total Affected & $\ldots$ & $\ldots$ & 203 & 32 & 62 & 297 \\
Total Examined & $\ldots$ & $\ldots$ & 322 & 84 & 200 & 606 \\
\hline$\%$ Affected & $\ldots$ & $\ldots$ & 67 & 38 & 31 & 49
\end{tabular}

Itu Settlement.

\begin{tabular}{lrrrrrr}
\multicolumn{2}{c}{ Type of Case } & & Men & Women & Cbildren & Total \\
Early Cases & $\ldots$ & $\ldots$ & 325 & 148 & I38 & 6 II \\
Advanced Cases & $\ldots$ & $\ldots$ & 338 & 156 & 94 & 588 \\
Total Affected & $\ldots$ & $\ldots$ & 663 & 304 & 232 & II 99 \\
Total Examined & $\ldots$ & $\ldots$ & 1075 & 507 & 550 & 2132 \\
\hline$\%$ Affected & $\ldots$ & $\ldots$ & 61 & 60 & 42 & 56
\end{tabular}

\section{Uzuakoli Settlement.}

These figures given exclude those patients (a) aged over 50 years, (b) with eight fingers severely contracted, (c) with six or more fingers badly contracted and more than two foreshortened, (d) post-operative cases. These patients numbered, possibly, ro to $15 \%$ of the cases noted; this would make the total number of affected patients approximately 200 , or $16 \%$ of the patients examined.

$$
\text { Type of Case Men Women Childien Total }
$$

$\begin{array}{lllllrr}\text { Early Cases } & \ldots & \ldots & 26 & 32 & \text { I5 } & 73 \\ \text { Advanced Cases } & \ldots & \ldots & 57 & 30 & 7 & 94 \\ \text { Total Affected } & \ldots & \ldots & 83 & 62 & 22 & 167\end{array}$

Early cases $=$ Contracture of two fingers or less.

Advanced cases $=$ Contracture of more than two fingers . 
PHYSICAL, THERAPY IN Lipkosy

SURVEYS (Continued)

Di:Taili:d Survi:y of Main-lin-Griffi: and Ni:Rvi: Involvi:mient.

(UZUAKoli)

\begin{tabular}{|c|c|c|c|c|c|}
\hline Type of Case & Men & Women & Children & Total & \\
\hline Pain only.. & 3 & I 2 & 3 & I8) & I90 \\
\hline Enl. Nerve & 32 & 7 & 26 & 65 ) & 'Potential' \\
\hline P. + Enl. Nerve ... & 32 & 30 & 45 & I07) & Cases \\
\hline $\begin{array}{l}\text { P. + E.N. + Atrophy } \\
\text { or Contracture }\end{array}$ & & & & & \\
\hline or Contracture & I3 & I3 & 8 & $34)$ & I 88 \\
\hline $\begin{array}{l}\text { (P) } \mathrm{E} . \mathrm{N} .+\mathrm{A}+\mathrm{C} \ldots \\
\text { (P) } \mathrm{E} . \mathrm{N} .+\mathrm{A}+\mathrm{C}+\end{array}$ & $2 \mathrm{I}$ & 20 & 7 & $48)$ & Cases \\
\hline $\begin{array}{l}\text { (P) } \quad \text { E.N. }+\mathrm{A}+\mathrm{C}+ \\
\text { Foreshortening }\end{array}$ & I3 & 6 & 6 & $25)$ & $\begin{array}{c}\text { showing } \\
\text { trophic }\end{array}$ \\
\hline A. or C. ... & IO & I2 & I & $23)$ & changes. \\
\hline Other Combinations & 27 & 23 & 5 & $55)$ & \\
\hline Total Affected .... & I5I & I 26 & IOI & 378 & \\
\hline Total Examined. & 280 & 203 & I95 & 678 & \\
\hline$\%$ Affected ... & 54 & 62 & 52 & 56 & \\
\hline
\end{tabular}

Norl: Both arms were examined in the case of each patient. As previously stated, two-thirds of the total number affected were bi-lateral cases, but for the purpose of the survey only one could be quoted. It was decided to quote the arm most severely affected. Therefore the figures given for "potential" cases are conservative. 